\title{
Investigation for Influences of Seepage on Mechanical Properties of Rocks Using Acoustic Emission Technique
}

\author{
Saisai Wu $\mathbb{D}^{1,2}$ Xiaohan Zhang, ${ }^{1}$ Junping $\mathrm{Li} \mathbb{D}^{1},{ }^{1}$ and Zhao Wang $\mathbb{D}^{1}$ \\ ${ }^{1}$ School of Resources Engineering, Shanxi Key Laboratory of Geotechnical and Underground Space Engineering, XAUAT, \\ Xian 710055, China \\ ${ }^{2}$ International Joint Research Laboratory of Henan Province for Underground Space Development and Disaster Prevention, HPU, \\ Jiaozuo 454003, China
}

Correspondence should be addressed to Junping Li; lijunping@xauat.edu.cn

Received 7 October 2020; Revised 26 October 2020; Accepted 29 October 2020; Published 23 November 2020

Academic Editor: Bin Gong

Copyright (c) 2020 Saisai Wu et al. This is an open access article distributed under the Creative Commons Attribution License, which permits unrestricted use, distribution, and reproduction in any medium, provided the original work is properly cited.

\begin{abstract}
The behavior of rock mass is governed by the properties of both the rock material and discontinuities in the rock mass. Surrounding environments including the existence of water also have a great influence on the behavior and mechanical properties of rocks. In this study, a novel-designed compression and seepage testing system, associated with an acoustic emission system, was designed and constructed. The changes in the specimens resulting from the uniaxial compression were monitored by an acoustic emission technique. The characteristics of the acoustic emission parameters at different stages including compaction and crack initiation, crack propagation, and catastrophic failure were analyzed. The existence of seepage had direct influences on the mechanical properties and failure patterns of the specimens. The specimens tested in pure compression conditions demonstrated strong burst proneness and ruptured into separate pieces, while for the specimens with seepage, no burst proneness was observed and the specimens tended to fail along a macroscopic shear failure plane. The highest average energy of the acoustic signal occurred at the stage of initial rupture of rock specimens, rather than at the stage of widespread rupture. The studies explored the possibilities of using the acoustic emission technique to investigate the problems associated with the seepage in geotechnical and rock engineering and provided meaningful results for further research in this field.
\end{abstract}

\section{Introduction}

Rock mechanics plays an important role in the design, construction, and performance assessment of various rock engineering fields such as tunnels, bridges, and mining operations [1-3]. The failure and damage characteristic of rocks is therefore one of the most intensively studied research topics in the field of rock engineering [4-6]. The behavior of rock mass is governed by the properties of both the rock material and discontinuities in the rock mass [7-9]. Surrounding environments such as the water also have great influences on the behavior and mechanical properties of rocks [10-12]. The interior of the rock generally contains natural defects in the crystal, micropores, and fissures between particles, native, secondary layering, and regulation, which provide the channel for the diffusion of the water [13-15]. The groundwater in the discontinuous surfaces could reduce the rock's antishear strength and the elastic yield limit through producing the external stress by the pore water pressure [16]. When the water pressure is greater than the contact pressure, the microcracks initiate and continue to develop reducing the stability of the rock mass.

The existence of the water could also affect the mechanical properties of the rock through altering the original chemical composition of the rock. Generally, due to the different interaction mechanisms of the negative and positive ions within the rocks, the negative and positive ions in the water would redistribute when the water flow through the rocks $[17,18]$. More specifically, negative ions in water are preferentially attracted by the particles in rock, which cause intricate alterations in the petrographical and mineralogical characteristics of rocks [19]. Due to the negative influences of the water on the strength and deformational properties of rocks, critical evaluations of physical-mechanical behavior 
of rocks under the effects of seepage are of significant relevance in geotechnical engineering structures [20-22]. However, due to the diversity of rock properties, randomness, ambiguity, and environmental complexity, the effect of seepage on the mechanical properties of rock is not systematically understood. To maintain the integrity and long-term stability of rock mass under water-rich conditions, understanding the influences of seepage on mechanical properties and failure process of rocks is quite necessary.

A number of studies have been carried out to evaluate the failure process of the rock through acoustic emission (AE) techniques [23-25]. Because of the nondestructive characteristic, AE techniques have drawn increased attention recently for characterizing the rock failure process. The number of AE events is related to the inelastic deformation of the rock [26]. The relative numbers of small and large AE events derived from the amplitude distribution obey the power law frequency-magnitude relation and correlate with the degree of damage localization $[27,28]$. In addition, the size, orientation, and mechanism of microcracks are indicated by source mechanism analysis [29]. Triaxial experiments carried out on basalt show excellent agreement between AE source locations of individual microcracks and the fault zone [30]. The aforementioned experiments show that $\mathrm{AE}$ is one of the promising tools to characterize the failure process of rocks. However, investigation into the effects of seepage on the failure process using AE techniques is still an emerging field which affects the stability of the geotechnical engineering structures.

In this study, in order to investigate the influences of seepage on mechanical properties and failure process of rocks, a novel-designed compression and seepage testing system that is capable of conducting the uniaxial compression testing on the rock specimens while applying the seepage was designed and constructed. The failure procedures of the rock specimens under the conditions with or without the effects of seepage were monitored by the AE technique in real time. The influences of the seepage on the mechanical parameters of the rock specimens were obtained. Comparisons of the recorded mechanical and acoustic signal parameters under the testing conditions with and without the effects of seepage were carried out. The results provided a new basis for the stability analysis of rock mass considering the influences of the seepage.

\section{Experimental Programs}

2.1. Specimens. The tested marble specimens were collected from a copper-iron mine in China. Typically, the specimens are characterized as fine-grain, coarser, and having soft texture good integrity with local small cracks. The structure surface contains silicon filling. Because marble generally contains impurities and calcium carbonate, it can be easily affected by the water [31]. In the preparation of the specimens, the rock mass with good integrity was collected and machined into cuboid with the dimension of $50 \mathrm{~mm} \times 50$ $\mathrm{mm} \times 100 \mathrm{~mm}$. The surfaces of the specimens were polished by a grinder, and its flatness and verticality were complying with the standard requirement. The parallelism deviation of the surfaces at both ends of the specimen was controlled less than 0.1 millimeter.

2.2. Experimental Systems. For the laboratorial tests, a noveldesigned compression and seepage testing system associated with AE testing system was constructed. The system was designed to evaluate the influences of seepage on mechanical properties of rocks using $\mathrm{AE}$ techniques at low strain rate. The testing system consists of three major parts including servo-controlled material testing system (MTS), AE21C acoustic transmitter, and seepage system. The schematic diagram and installed testing system are shown in Figures 1 and 2. The compression capability of the servo-controlled MTS is 200 tons. The AE21C acoustic transmitter is computer-controlled which supports Fast Fourier Transformation, correlation analysis, transfer functions, and other digital signal processing work. The record transmission signal can be automatically processed and also the output impact count, ring ingress count, the main frequency value, and its corresponding magnitude. The sensor with $20 \mathrm{kHz}$ broadband was used to capture sound transmission signals and the AE waveform.

The seepage system is used to apply a continuous water cycling system to the specimens during the tests. For the design of the seepage system, a square-shaped sealing strip made from rubber was evenly arranged and attached in the upper section of the specimen. To facilitate the exposure and diffusion of the water into the specimen, a specialised designed water spray system was constructed with a number of spray nozzles uniformly installed inside the sealing strips. The spray nozzles could provide the water mist that would penetrate evenly into the test specimens. A nitrogen cylinder was used to provide the water pressure to the reticulation pipes that connect the spray nozzles and the water tank. Different with the saturated cases, the application of the seepage system simulated the real in situ scenario that the water continually penetrated into the rock.

2.3. Testing Procedures. Once the specimens were prepared, all specimens were tagged and photographed. To accurately determine the effects of seepage on the mechanical properties of the specimens, uniaxial compression tests on the specimens under the conditions with or without the effects of seepage were carried out. All the tests were conducted in a quiet indoor environment to avoid noise disturbances. The test scenarios without the effects of the seepage were conducted as reference tests. For the reference tests, the specimens were loaded in pure compression condition using the servo-controlled MTS. Prior to applying the loads, the specimen was tightly secured between two loading platens of the servo-controlled MTS with two adaptors. The rubber gaskets with the thickness of 10 millimeters were put between the end of the specimen and the loading platens, to avoid noise interference due to friction at the end of the specimen when loading. For each test, two sensors were pasted on the central position of the two opposite sides of the cuboid specimens using Vaseline. During the tests, the compression applied on the specimens was increased at $0.02 \mathrm{KN}$ every second until the failure occurred. The failure procedures of the rock 


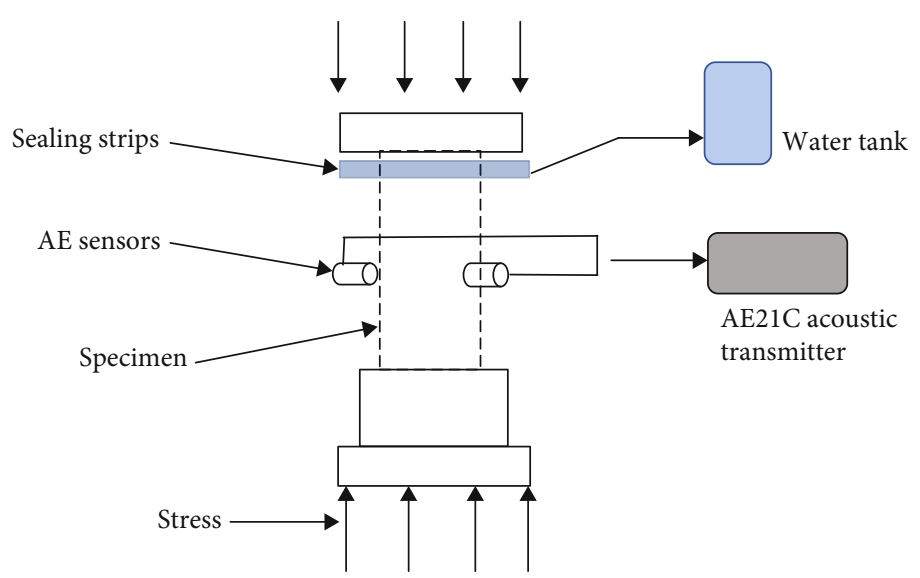

Figure 1: Schematic view of the testing system.

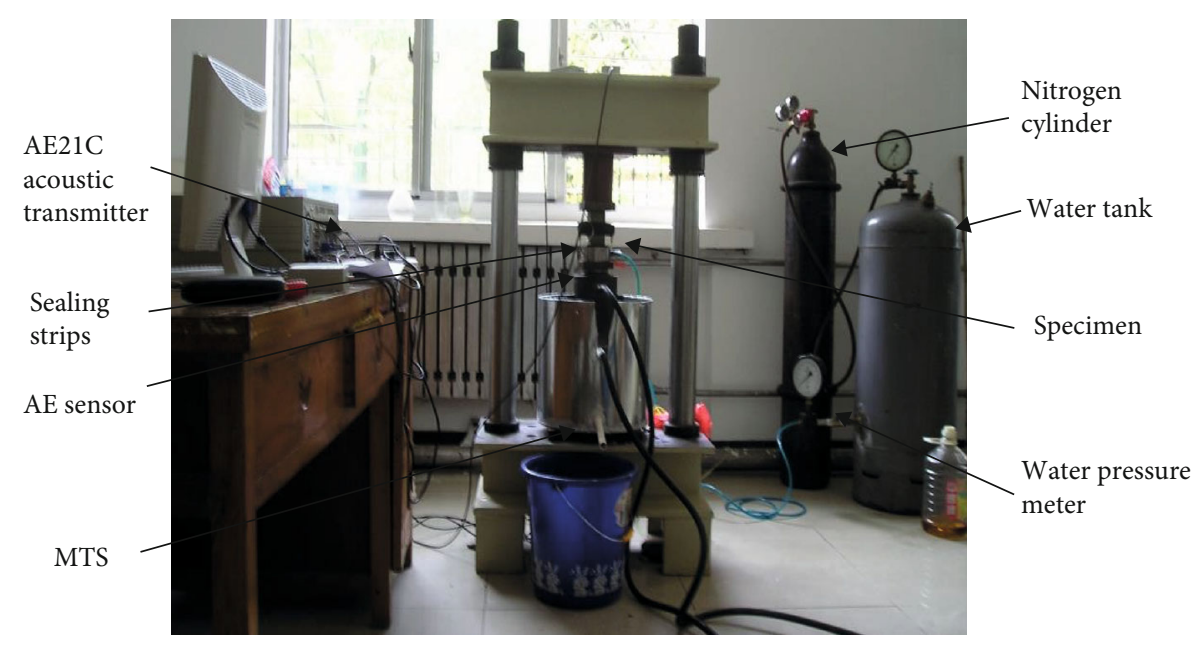

FIgURe 2: A photograph of the testing system.

specimens were monitored by the AE technique in real time. The sampling frequency was $2 \mathrm{MHz}$, and the amplification was $40 \mathrm{~dB}$. To eliminate the effects of noise interference due to water application by the spray nozzles, the threshold value of acoustic emission was selected at $80 \mathrm{~dB}$ which was slightly above the background noises. The acoustic parameters including number of events, hits, and energy were automatically proceeded and recorded.

For the tests considering the effects of seepage, prior to applying the loads, the specimen was exposed to the water spray for a certain time using the designed continuous water cycling system in order to make sure water was penetrated into the specimens and formed a continual water diffusion path. To facilitate the exposure and diffusion of the water into the specimen, a constant water pressure of $0.2 \mathrm{MPa}$ was applied to the spray nozzles by the application of the nitrogen cylinder. After 24-hour exposure, the specimens were loaded in compression at the increasing stress rate of $0.02 \mathrm{KN}$ every second until the failure occurred. The failure procedures of the specimens were monitored by the AE technique in real time. The design of the continuous water cycling system was able to simulate the real in situ scenario that the water continually penetrated into the rock. Additionally, three specimens were tested in each condition to eliminate the effects of any scatter on the test results.

\section{Experimental Results and Analysis}

3.1. Mechanical Properties. The stress-strain curve of the rock specimens under the uniaxial compression tests with or without the effects of the seepage is obtained and displayed in Figures 3 and 4, respectively. Based on the results, elastic modulus and Poisson's ratio were calculated and the results are summarized in Table 1 . It can be seen from the test results that the seepage has significant influences on the mechanical properties of the specimens. For the specimens tested in the pure compression conditions, the average ultimate compression strength was $32.8 \mathrm{MPa}$, while the average ultimate compression strength of the specimens tested in the conditions with the seepage was around $26.6 \mathrm{MPa}$, decreased by $23.3 \%$ compared to that in the pure compression conditions. The average strain of the specimens under pure compression conditions was $1.63 \%$, while this value was $2.29 \%$ with the effects of seepage. The elastic modulus of the specimen in pure compression conditions $(20.14 \mathrm{GPa})$ was around twice of that in the conditions with the seepage $(11.62 \mathrm{GPa})$. Even though 


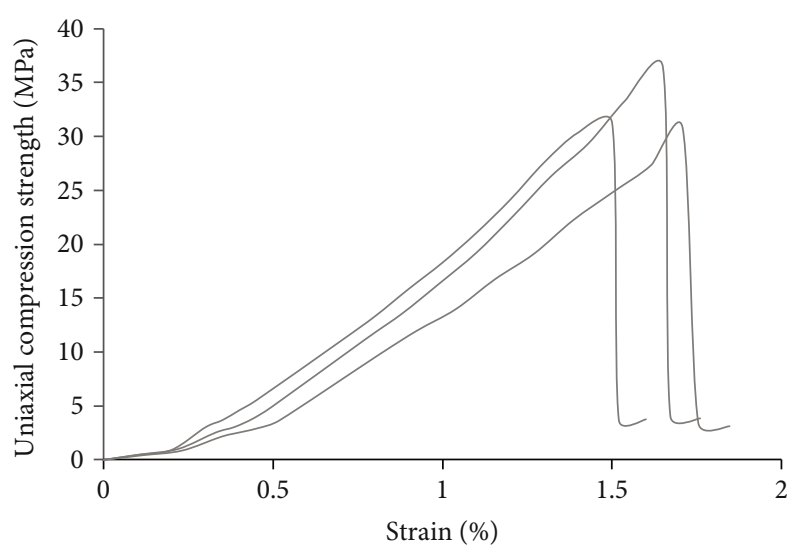

FIGURE 3: The stress-strain curve of the specimens in pure compression tests.

the uniaxial compression strength of the specimens varied, the test results remained reasonably consistent and repeatable.

The differences in the compressive strength and elastic modulus for the rock with or without the effects of seepage may be related to the petrographical and mineralogical properties [32]. The specimens used in this study are characterized as fine-grain and coarser and having soft texture. The structure surface of the specimens contains silicon filling which could be easily affected by the seepage [31]. When the water diffused into the micropores and fissures in the rocks, the external stress may be produced by the pore water pressure, reducing the yield strengths of the rock. Additionally, the diffused water could alter the mineralogical properties of the rocks and formed new water-soluble substances [33]. As a result, the original structure of rock was destroyed and the cementation force between particles was weakened. Under the compression conditions, the reduced connection force between particles of the original structure of rock facilitated the initiation of the microcracks in the rock and resulted in the macroscopic failure of the rock at low stress magnitudes. The failure pattern of the specimens under the effects of the seepage had a creeping tendency. The average deformation of the specimens at the failure time under the effects of seepage was larger than that under pure compression conditions. The low elastic modulus of the specimens under the effects of the seepage confirmed negative effects of water on the mechanical properties of the rock and also suggested that the marble was sensitive to the effects of the seepage.

3.2. Failure Patterns. The failure patterns of the specimens under the uniaxial compression tests without or with the effects of the seepage are displayed in Figures 5 and 6, respectively. All of the specimens under uniaxial compression showed apparently macroscopic brittle behavior evidenced by the visible spalls and axial failure planes. The dominant failure pattern of the specimen was regarded as axial splitting. However, differences in the failure mechanism of the rock specimens without or with the effects of the seepage were also observed. The specimens tested in pure compression condi- tions demonstrated strong burst proneness and ruptured into separate pieces, while for the specimens in the conditions with seepage, no burst proneness was observed and the specimens tended to fail along a macroscopic shear failure plane. At the failure time, the specimens did not split into separate pieces.

It is commonly recognized that rock failures were related to the initiation and propagation of microcracks randomly in the rock. The initiation and propagation of microcracks in the rock are influenced by many factors, such as the experimental conditions and the distribution of external loading $[34,35]$. The difference in the failure patterns of the specimens without or with the effects of the seepage could account for the negative effects of water on the mechanical properties of rock. Under the pure compression conditions, the failure initially started with the opening of the fissure-based fracture and gradually turned into shear damage when the main crack formed $[36,37]$. Due to the high stiffness of the rock, the final rupture showed the characteristics of the sudden catastrophic brittle destruction with strong burst proneness. Under the effects of the seepage, the connection force between particles and the original structure of rock was destroyed. The reduced connection force between particles of the original structure of rock facilitated the initiation of the microcracks in the rock. Microcracks propagated and interacted with each other forming the macroscopic failure planes at the weakest direction rather than raptured into pieces [38-40]. This observation was also consistent with the higher average strain at the failure time compared to that in pure compression. Therefore, the specimens tested in the conditions without or with the effects tend to fail in different patterns with different degrees of burst proneness.

3.3. Acoustic Emission Parameters. The characteristics of the measured acoustic signals during the experiments showed similar trends, and one of the detailed AE measurements was presented. The accumulated acoustic activities recorded in the tests with or without seepage are displayed in Figures 7 and 8, respectively. The accumulated acoustic activities showed the presence of three stages in the failure process of the rock specimens. At the first stage, there were no significant $\mathrm{AE}$ activities until the applied stress was around $24 \mathrm{MPa}$ in the pure compression tests and $14 \mathrm{MPa}$ under the effects of the seepage. After that, an increase of $\mathrm{AE}$ activities was observed and it continued to grow progressively until the applied stress reached around 90\% of maximum load. When the applied stress reached around $30 \mathrm{MPa}$ and $24 \mathrm{MPa}$ in the condition with and without seepage, the number of the AE activities increased significantly. Generally, under the effects of the seepage, the level of received AE activities were generally high throughout the whole test procedures.

The failure processes of the rock under compression conditions are generally characterized by three stages including compaction and crack initiation, crack propagation, and catastrophic failure. It was suggested that $24 \mathrm{MPa}$ and $14 \mathrm{MPa}$ are corresponding to the stage of compaction and crack initiation with or without seepage, respectively. Due to the existence of natural defects and micropores in the interior of 


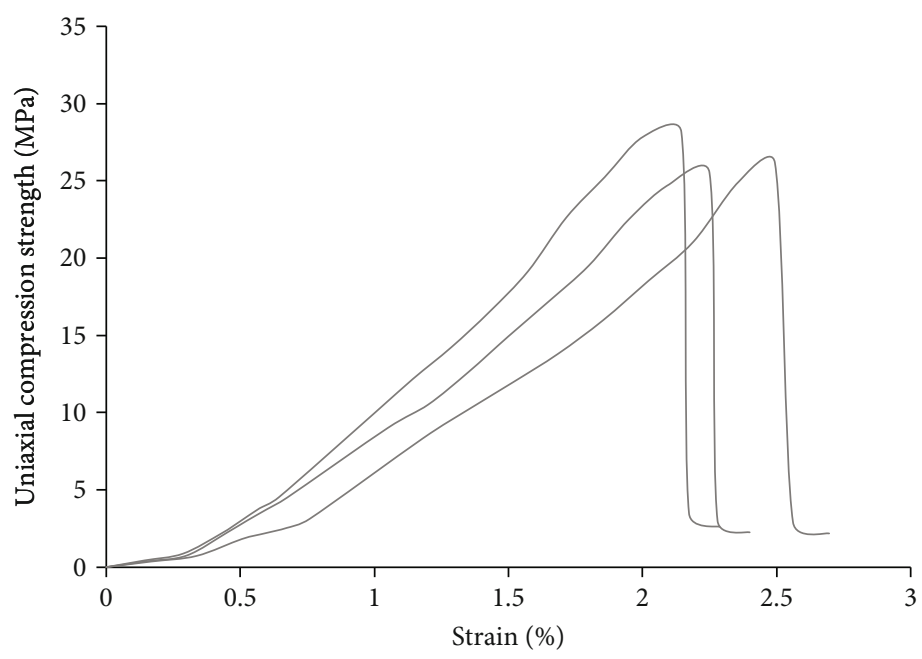

FIgURE 4: The stress-strain curve of the specimens with the seepage.

TABLE 1: The variation of mechanical parameters.

\begin{tabular}{|c|c|c|c|c|c|}
\hline $\begin{array}{l}\text { Testing conditions (hydromechanical } \\
\text { coupling) }\end{array}$ & $\begin{array}{l}\text { Uniaxial compression strength } \\
\qquad(\mathrm{MPa})\end{array}$ & $\begin{array}{l}\text { Mean value } \\
\quad(\mathrm{MPa})\end{array}$ & $\begin{array}{c}\text { Strain } \\
(\%)\end{array}$ & $\begin{array}{l}\text { Mean value } \\
(\%)\end{array}$ & $\begin{array}{l}\text { Elastic modulus } \\
\qquad(\mathrm{GPa})\end{array}$ \\
\hline & 36.43 & & 1.65 & & \\
\hline \multirow[t]{3}{*}{ Without } & 30.78 & 32.83 & 1.71 & 1.63 & 20.14 \\
\hline & 31.28 & & 1.54 & & \\
\hline & 26.16 & & 2.49 & & \\
\hline \multirow[t]{2}{*}{ With } & 25.52 & 26.61 & 2.25 & 2.29 & 11.62 \\
\hline & 28.16 & & 2.14 & & \\
\hline
\end{tabular}
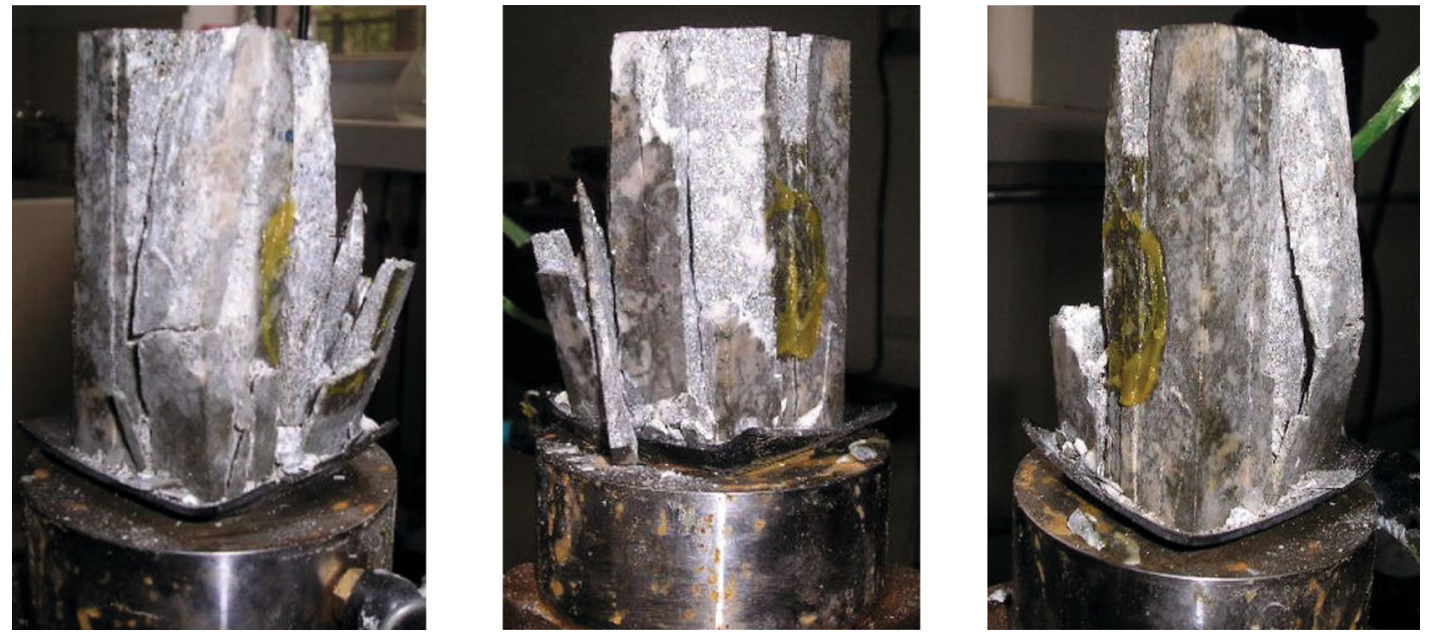

FIgURE 5: Failure patterns of the specimens under pure uniaxial compression tests.

the rock, the specimens were compacted at this stage and no significant AE activities were recorded at this stage. With the increasing of the applied stress intensities, the cumulative damage by the applied stress resulted in the microcrack coalescence within the rock. Once the sliding of the microcrack coalescence occurred, the transverse and longitudinal cracks propagated along the length of the initial crack [38-40]. Therefore, at the stage of crack propagation, the initial rup- ture of rock occurred producing a large number of new cracks in the interior of rock, and an increasing number of acoustic signals was recorded. The third stage was regarded as the catastrophic failure which corresponded to the applied stress of $30 \mathrm{MPa}$ and $24 \mathrm{MPa}$ with or without seepage. At this stage, the produced new cracks in the interior of rock interacted with each other forming the main fracture at the weakest direction. Once the specimens cannot support the applied 

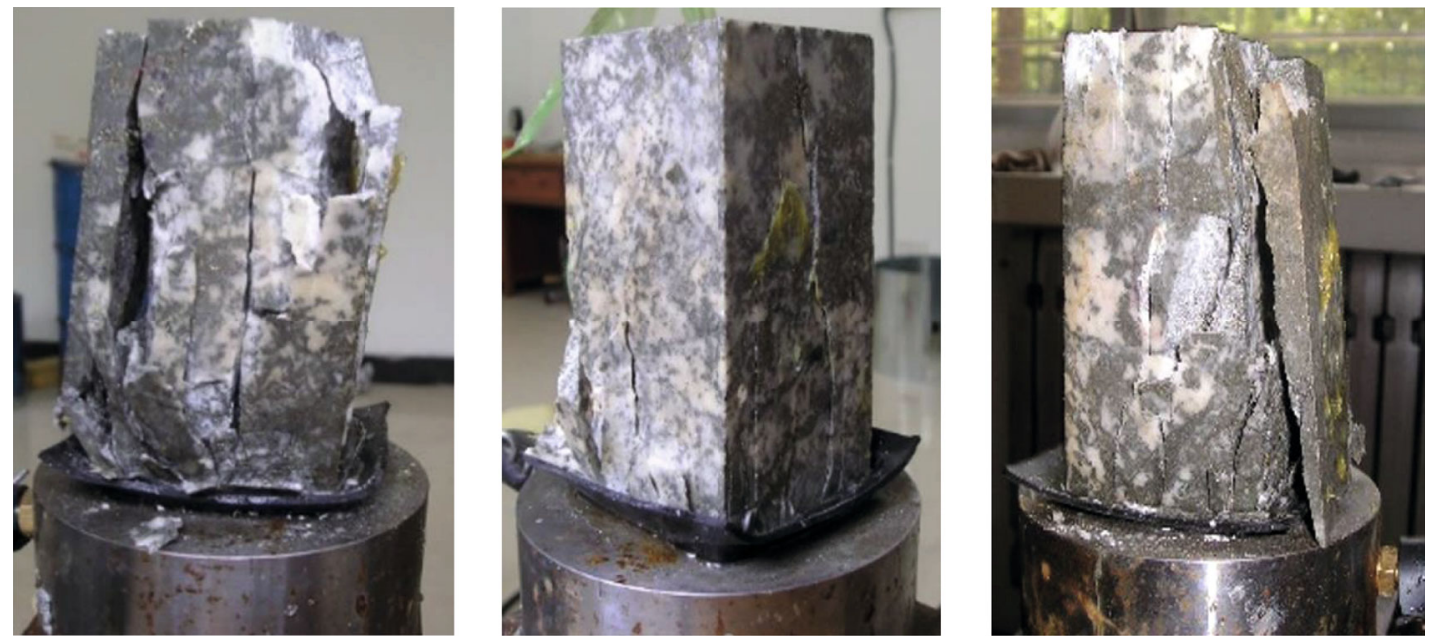

FIGURE 6: Failure patterns of the specimens under compression tests with the seepage.

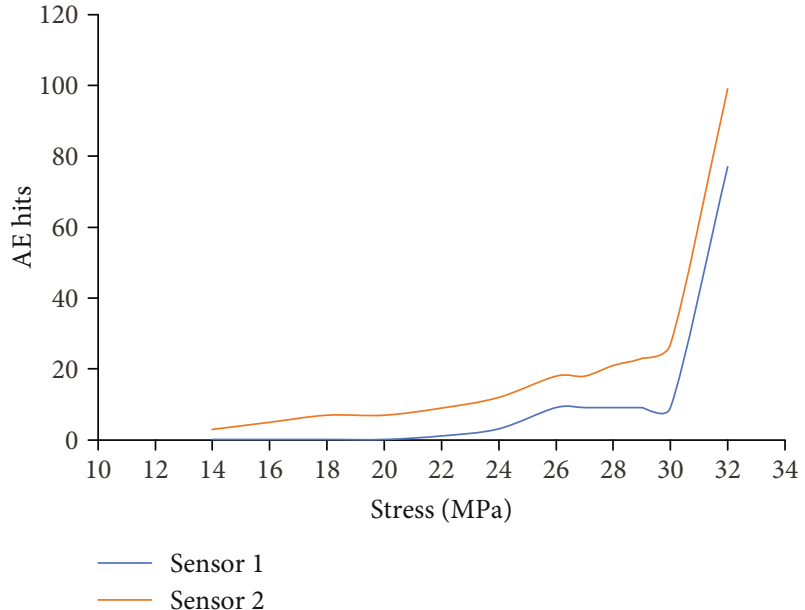

FIGURE 7: Evolution of acoustic activities in pure compression tests.

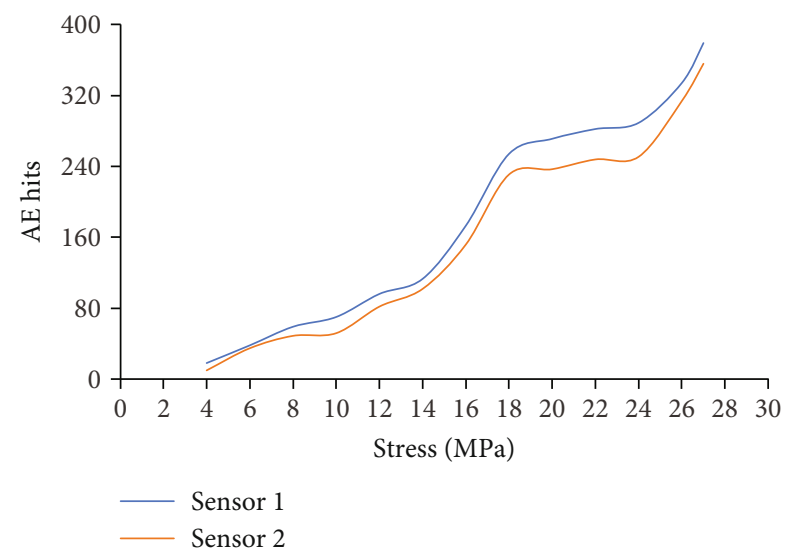

FIGURE 8: Evolution of acoustic activities under the effects of the seepage.

loads, catastrophic failure of the rock occurred and the specimens ruptured into pieces, during which significant $\mathrm{AE}$ activities were recorded.
The main frequency distribution of $\mathrm{AE}$ activities under pure compression conditions was analyzed. At the stress intensity of $24 \mathrm{MPa}$ where the crack initiated, the main frequency distribution of the acoustic signal ranged from $0.24 \mathrm{kHz}$ to $36.4 \mathrm{kHz}$ (Figure 9(a)). The frequency of the most recorded signal was lower than $10 \mathrm{kHz}$. The maximum frequency of the recorded signal was $36.4 \mathrm{kHz}$. When the stress intensity was increased to $30 \mathrm{MPa}$ where the catastrophic failure of the rock occurred, the frequency of the acoustic signal increased dramatically ranging from $0.98 \mathrm{kHz}$ to $77.6 \mathrm{kHz}$ (Figure 9(b)). The proportion of low-frequency components was low, and the frequency of the most recorded signal was higher than $10 \mathrm{kHz}$. The maximum frequency of the recorded signal was $77.6 \mathrm{kHz}$ which was around twice of that under the stress of $24 \mathrm{Mpa}$.

Under the effects of seepage, the frequency distribution of AE activities during the failure process was lower than that in pure compression tests. At the applied stress of $16 \mathrm{Mpa}$ where the crack initiated, the frequency distribution ranged from $0.5 \mathrm{kHz}$ to $16.4 \mathrm{kHz}$. The frequency distribution of the acoustic transmit signal was wide, and the proportion of frequency components around $10 \mathrm{kHz}$ exceeded $50 \%$ (Figure 10(a)). At stress intensities of $22 \mathrm{Mpa}$ in which catastrophic failure of the rock occurred, the frequency distribution of the received signals ranged from $2.1 \mathrm{kHz}$ and $17.8 \mathrm{kHz}$, which was similar with that under the stress of $16 \mathrm{MPa}$ (Figure 10(b)).

It was observed that the main frequency of the acoustic signal was increased with the increasing loads under the pure compression conditions. The maximum frequency of the recorded signal at the stage of catastrophic failure $(77.6 \mathrm{kHz})$ was around twice of that at the stage of crack initiation $(36.4 \mathrm{kHz})$. This significant difference in the main frequency distribution of the acoustic signal at the different failure stages demonstrated the potential correlation between the frequency of acoustic signal and failure status of rock specimens. Compared with the sharp increases of the main frequency of acoustic signal at different stages under pure compression conditions, the main frequency of the received signals is basically stable at different stress levels under the under the effects of seepage. 


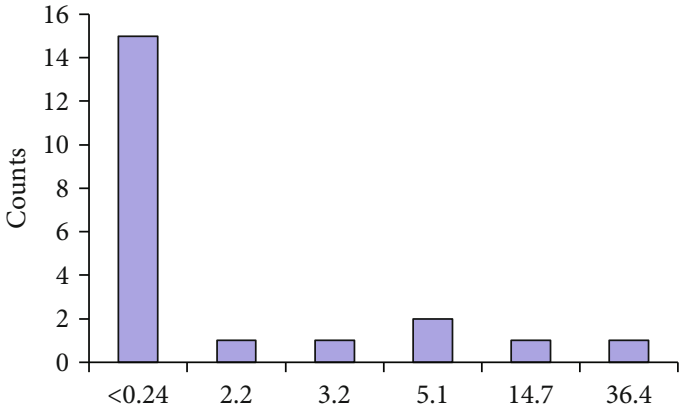

(a) Frequency distribution at $24 \mathrm{MPa}(\mathrm{kHz})$

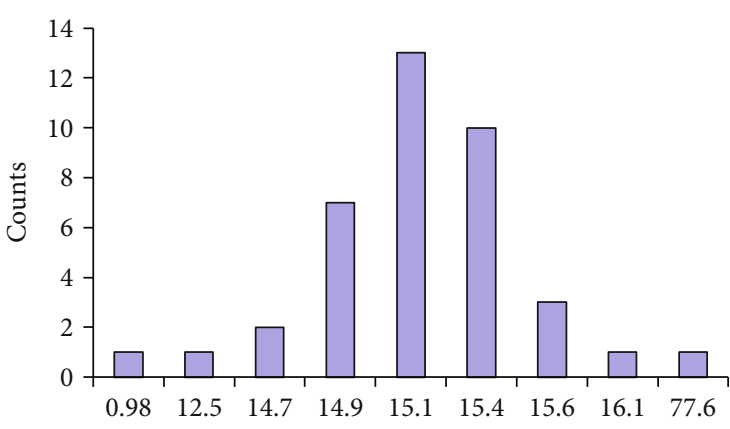

(b) Frequency distribution at $30 \mathrm{MPa}(\mathrm{kHz})$

FIgure 9: The main frequency distribution of acoustic signal: (a) $26 \mathrm{MPa}$; (b) $32 \mathrm{MPa}$.

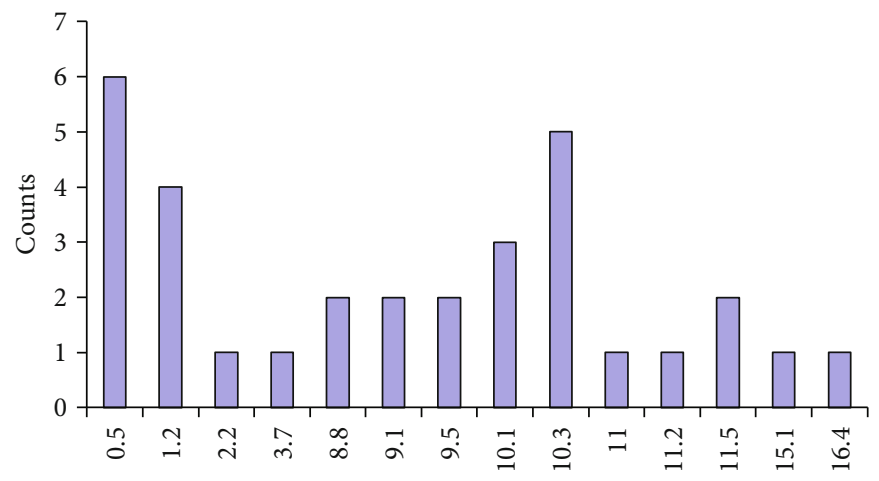

(a) Frequency distribution at $16 \mathrm{MPa}(\mathrm{kHz})$

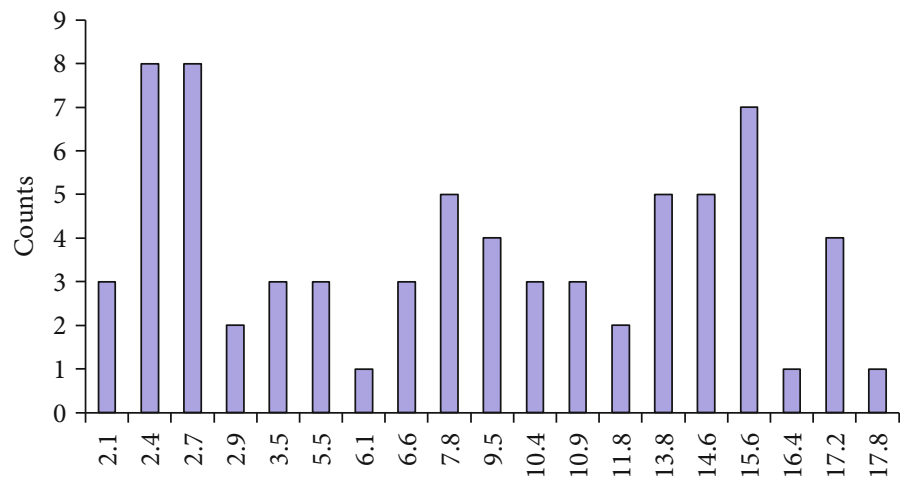

(b) Frequency distribution at $22 \mathrm{MPa}(\mathrm{kHz})$

Figure 10: The main frequency distribution of marble under the effects of seepage.

The relationships between the average energy of the recorded acoustic signal and the applied stress intensities were studied (Figure 11). The average energy of a single ring is the ratio of energy counting rate to ring counting rate. It was observed that at the applied stress of $24 \mathrm{Mpa}$ under pure compression conditions, the average energies of a single ring reached the first peak at 12.80. Under the effects of seepage, the average energy reached the first peak of 11.46 at the applied stress of $16 \mathrm{Mpa}$. This observation demonstrated that the acoustic signals with large amplitudes and energy mainly occurred at the stage of crack initiation and propagation. The average energy reached the second peak at the applied stress intensities of $32 \mathrm{Mpa}$ and $24 \mathrm{Mpa}$ under the conditions with or without the effects of seepage, respectively. The values of the average energies at the second peak were smaller than those at the first peak.

The values of the average energies of the signals increased with the increasing of the applied stress until the stress reached the peak at $16 \mathrm{MPa}$ and $24 \mathrm{MPa}$ with and without the effects of seepage. During this period, the natural defects and micropores in the interior of the rock were compacted and the cumulative damage by the applied stress resulted in the microcrack coalescence. With the increasing of the applied stress, the sliding of the microcrack coalescence at the elastic deformation stage occurred, leading to the initial rupture of rock specimens. A large number of the new transverse and longitudinal cracks along the length of the initial crack were produced in the interior of rock, and the average 


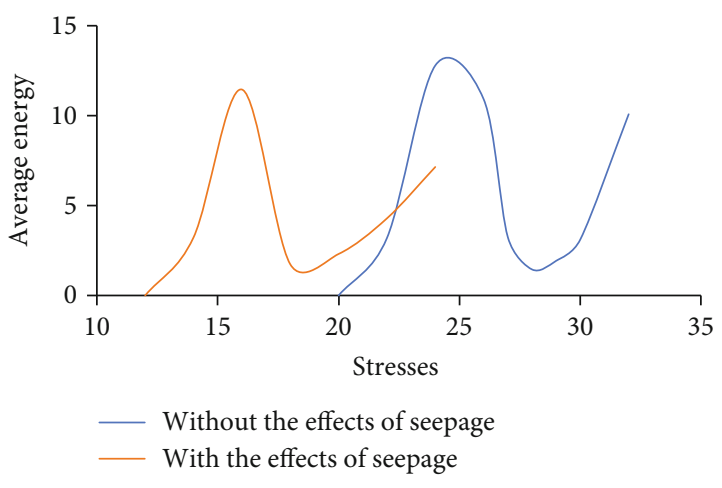

FIGURE 11: The average energy-stress curve.

energies reached the greatest. After that, the values of the average energies tended to decrease. At the stresses of $20 \mathrm{MPa}$ and $32 \mathrm{MPa}$ with and without the effects of seepage, catastrophic failure of the specimens occurred and the average energy reached the second peak.

\section{Discussions}

Under the pure compression conditions, the specimens showed the characteristics of the sudden catastrophic brittle destruction with strong burst proneness. The main frequency of the received signal generally increased with the increasing of applied stress intensity. However, under the effects of the seepage, the specimen showed progressive failure mode and has a creeping tendency and the main frequency of the received signals was basically stable at different stress levels. This observation may indicate that the main frequency of acoustic emission during the failure processes is affected not only by the applied stress intensities but also by many other environmental factors that affected the mechanical properties of the rock. With the effects of seepage, the stiffness decreased and the specimens did not show burst proneness. The failure patterns of the specimens showed the characteristics of the gradual destruction with high deformation at the failure time. This observation may account for the relative stable frequency of the received signals which is at different stress levels.

The average energies of the recorded signals under the pure compression conditions were generally higher than those under the effects of seepage. Under the effects of seepage, the connection force between particles and the original structure of rock was destroyed, resulting in the specimens failing in a progressive failure mode with a large degree of deformation. Generally, the existence of the seepage could affect the connection force between particles of the original structure of rock through producing the external stress by the pore water pressure and altering the original chemical composition of the rock. The interior of the rock generally contains natural defects within the rock. When the water flows through natural defects within the rocks, the negative and positive ions in the water would redistribute, due to the different interaction mechanisms of the negative and positive ions within the rocks [41]. Negative ions in water are preferentially attracted by the particles in rock which cause intri- cate alterations in the petrographical, mineralogical, and mechanical properties of rocks $[41,42]$. Additionally, the diffusion of the water in the defects could reduce the rock's antishear strength and the elastic yield limit through producing the external stress by the pore water pressure [42, 43]. As a result, the original structure of rock was destroyed and the cementation force between particles was weakened. The elastic modulus of the specimen in pure compression conditions is around twice of that in the conditions with the seepage. The specimens in the pure compression conditions showed obvious brittle destruction and ruptured into separate pieces with a strong violent burst proneness. Previous researchers described that acoustic signals are generated by the rapid release of localized energy when they are stressed or deformed [26]. The difference of the failure modes as well as the higher elastic modulus of the specimens could account for the higher average energy of the acoustic signals during the failure process under the pure compression conditions.

Regardless of the effects of the seepage, the average energy of the signals reached the greatest at the stage of initial rupture rather than the stage of widespread ruptures. The failure of the rock initially started with the opening of the fissure-based fracture and gradually turned into shear damage when the main crack formed $[44,45]$. At the stage of the initial rupture of rock specimens, microcracks propagated producing a large number of new cracks in the interior of rock. The produced new cracks interacted with each other forming the main crack and failure planes at the weak directions. AE arises primarily from either the formation of microfractures or the opening, closure, or sliding motion of preexisting fractures [46]. It was suggested that at the time when the new cracks interacted with each other forming the main crack, the acoustic signals with the highest average energy were released at this stage. At the stages of the catastrophic failure, the initiation and propagation of the cracks in the interior of specimens had been basically completed, leading to the lower average energy of the acoustic signals. Additionally, the lower average energy of the acoustic signals at the catastrophic failure stage may cause by the attenuation of signal propagation due to the microfracture network formed by fracture, since using the acoustic emission monitoring to evaluate the stability of rock project is very complex. The highest average energy at the stage of initial rupture of rock, rather than at the stage of widespread rupture, can be useful for the early detection of rock failure at high stress situation.

\section{Conclusions}

A novel-designed compression and seepage testing system associated with the AE testing system was designed and constructed which was capable of simulating the real in situ scenario that the water continually penetrates into the rock. Using the designed testing system, uniaxial compression tests on the specimens under the conditions with or without the effects of seepage were carried out. The results showed that the existence of seepage had direct influences on the mechanical properties and failure patterns of rock. The elastic modulus of the specimen in pure compression conditions was 
around twice of that in the conditions with the seepage. Under the effects of the seepage, the failure patterns of the specimens had a creeping tendency and tended to fail along a macroscopic shear failure plane, while the specimens tested in pure compression conditions demonstrated strong burst proneness and ruptures into separate pieces. It was identified that the main frequency of the received signal generally increased with the increasing of applied stress intensity under the pure compression, while it was basically stable at different stress levels under the effects of seepage. Regardless of the effects of the seepage, the average energy of the signals reached the greatest at the stage of initial rupture rather than the stage of widespread ruptures which was very important for the early detection of rock failure at high stress situation. The studies undertaken not only provided a controlled environment for the evaluation of rock failure procedures using acoustic emission but also provided meaningful results for the understanding of the influences of seepage on mechanical properties and failure patterns of rocks.

\section{Data Availability}

The data used in this study are available from the corresponding author upon request.

\section{Conflicts of Interest}

The authors declare that they have no conflicts of interest.

\section{Acknowledgments}

This paper is funded by the National Natural Science Foundation of China (52004196); Department of Education, Shanxi Province, Special Research Plans (19JK0454); Science and Technology Bureau of Beilin, Xi'an (GX2016).

\section{References}

[1] A. M. Ferrero, "The shear strength of reinforced rock joints," International Journal of Rock Mechanics and Mining Sciences, vol. 32, no. 6, pp. 595-605, 1995.

[2] J. D. Hutchinson and M. S. Deiderichs, Cablebolting in Underground Mines, BiTech, British Columbia, Canada, 1996.

[3] Z. T. Bieniawski, "Mechanism of brittle fracture of rock," International Journal of Rock Mechanics and Mining Sciences \& Geomechanics Abstracts, vol. 4, no. 4, pp. 407-423, 1967.

[4] Y. Li, C. Tang, D. Li, and C. Wu, "A new shear strength criterion of three-dimensional rock joints," Rock Mechanics and Rock Engineering, vol. 53, no. 3, pp. 1477-1483, 2020.

[5] S. Wu, J. Li, J. Guo, G. Shi, Q. Gu, and C. Lu, "Stress corrosion cracking fracture mechanism of cold-drawn high-carbon cable bolts," Materials Science and Engineering A-Structural Materials Properties Microstructure and Processing, vol. 769, article 138479, 2020.

[6] P. Tapponnier and W. F. Brace, "Development of stressinduced microcracks in westerly granite," International Journal of Rock Mechanics and Mining Sciences \& Geomechanics Abstracts, vol. 13, no. 4, pp. 103-112, 1976.
[7] C. R. Windsor, "Rock reinforcement systems," International Journal of Rock Mechanics and Mining Sciences, vol. 34, no. 6, pp. 919-951, 1997.

[8] Q. He, Y. Li, D. Li, and C. Zhang, "Microcrack fracturing of coal specimens under quasi-static combined compressionshear loading," Journal of Rock Mechanics and Geotechnical Engineering, vol. 12, no. 5, pp. 1014-1026, 2020.

[9] B. Gong, Y. Jiang, P. Yan, and S. Zhang, "Discrete element numerical simulation of mechanical properties of methane hydrate-bearing specimen considering deposit angles," Journal of Natural Gas Science and Engineering, vol. 76, article 103182, 2020.

[10] J. Liu, W. Chen, T. Liu, J. Yu, J. Dong, and W. Nie, "Effects of initial porosity and water pressure on seepage-erosion properties of water inrush in completely weathered granite," Geofluids, vol. 2018, Article ID 4103645, 11 pages, 2018.

[11] S. Wu, H. L. Ramandi, H. Chen, A. Crosky, P. Hagan, and S. Saydam, "Mineralogically influenced stress corrosion cracking of rockbolts and cable bolts in underground mines," International Journal of Rock Mechanics and Mining Sciences, vol. 119, pp. 109-116, 2019.

[12] S. R. Wang, H. G. Xiao, Z. S. Zou, C. Cao, Y. H. Wang, and Z. L. Wang, "Mechanical performances of transverse rib bar during pull-out test," International Journal of Applied Mechanics, vol. 11, no. 5, article 1950048, 2019.

[13] S. Wu, H. Chen, P. Craig et al., "An experimental framework for simulating stress corrosion cracking in cable bolts," Tunnelling and Underground Space Technology, vol. 76, pp. 121-132, 2018.

[14] B. Gong, Y. Jiang, and L. Chen, "Feasibility investigation of the mechanical behavior of methane hydrate-bearing specimens using the multiple failure method," Journal of Natural Gas Science and Engineering, vol. 69, article 102915, 2019.

[15] Y. Li, C. Wu, and B. A. Jang, "Effect of bedding plane on the permeability evolution of typical sedimentary rocks under triaxial compression," Rock Mechanics and Rock Engineering, vol. 53, p. 9, 2020.

[16] S. R. Wang, X. G. Wu, Y. H. Zhao, P. Hagan, and C. Cao, "Evolution characteristics of composite pressure-arch in thin bedrock of overlying strata during shallow coal mining," International Journal of Applied Mechanics, vol. 11, no. 3, article 1950030, 2019.

[17] H. Kang, Y. Wu, F. Gao, J. Lin, and P. Jiang, "Fracture characteristics in rock bolts in underground coal mine roadways," International Journal of Rock Mechanics and Mining Sciences, vol. 62, pp. 105-112, 2013.

[18] R. Singh, P. K. Mandal, A. K. Singh, and T. N. Singh, "Cablebolting-based semi-mechanised depillaring of a thick coal seam," International Journal of Rock Mechanics and Mining Sciences, vol. 38, no. 2, pp. 245-257, 2001.

[19] A. Basu, T. B. Celestino, and A. A. Bortolucci, "Evaluation of rock mechanical behaviors under uniaxial compression with reference to assessed weathering grades," Rock Mechanics and Rock Engineering, vol. 42, no. 1, pp. 73-93, 2009.

[20] S. Wu, M. Northover, P. Craig, I. Canbulat, P. C. Hagan, and S. Saydam, "Environmental influence on mesh corrosion in underground coal mines," International Journal of Mining Reclamation and Environment, vol. 32, no. 8, pp. 519-535, 2018.

[21] S. Wu, J. Guo, G. Shi, J. Li, and C. Lu, "Laboratory-based investigation into stress corrosion cracking of cable bolts," Materials, vol. 12, no. 13, p. 2146, 2019. 
[22] S. R. Wang, X. G. Wu, J. H. Yang, J. Q. Zhao, and F. L. Kong, "Mechanical behavior of lightweight concrete structures subjected to 3D coupled static-dynamic loads," Acta Mechanica, vol. 231, no. 11, pp. 4497-4511, 2020.

[23] X.-T. Feng, S. Chen, and H. Zhou, "Real-time computerized tomography (CT) experiments on sandstone damage evolution during triaxial compression with chemical corrosion," International Journal of Rock Mechanics and Mining Sciences, vol. 41, no. 2, pp. 181-192, 2004.

[24] C. S. Kao, F. C. S. Carvalho, and J. F. Labuz, "Micromechanisms of fracture from acoustic emission," International Journal of Rock Mechanics and Mining Sciences, vol. 48, no. 4, pp. 666673, 2011.

[25] I. L. Meglis, T. Chow, C. D. Martin, and R. P. Young, “Assessing in situ microcrack damage using ultrasonic velocity tomography," International Journal of Rock Mechanics and Mining Sciences, vol. 42, no. 1, pp. 25-34, 2005.

[26] D. A. Lockner, J. D. Byerlee, V. Kuksenko, A. Ponomarev, and A. Sidorin, "Quasi-static fault growth and shear fracture energy in granite," Nature, vol. 350, no. 6313, pp. 39-42, 1991.

[27] A. Schiavi, G. Niccolini, P. Tarizzo, A. Carpinteri, G. Lacidogna, and A. Manuello, "Acoustic emissions at high and low frequencies during compression tests in brittle materials," Strain, vol. 47, Supplement 2, pp. 105-110, 2011.

[28] M. V. M. S. Rao and K. Lakshmi, "Amplitude distribution analysis of acoustic emissions and investigation of the development of brittle fracture in rock," Indian Journal of Pure and Applied Physics, vol. 44, pp. 820-825, 2006.

[29] V. Rudajev, J. Vilhelm, and T. Lokajíček, "Laboratory studies of acoustic emission prior to uniaxial compressive rock failure," International Journal of Rock Mechanics and Mining Sciences, vol. 37, no. 4, pp. 699-704, 2000.

[30] P. M. Benson, B. D. Thompson, P. G. Meredith, S. Vinciguerra, and R. P. Young, "Imaging slow failure in triaxially deformed Etna basalt using 3D acoustic-emission location and X-ray computed tomography," Geophysical Research Letters, vol. 34, no. 3, 2007.

[31] C. Gökceoğlu, R. Ulusay, and H. Sönmez, "Factors affecting the durability of selected weak and clay-bearing rocks from Turkey, with particular emphasis on the influence of the number of drying and wetting cycles," Engineering Geology, vol. 57, no. 3-4, pp. 215-237, 2000.

[32] A. Momeni, S. S. Hashemi, G. R. Khanlari, and M. Heidari, "The effect of weathering on durability and deformability properties of granitoid rocks," Bulletin of Engineering Geology and the Environment, vol. 76, no. 3, pp. 1037-1049, 2017.

[33] J. Zou, Y. M. Sheng, M. Y. Xia, and F. Wang, "A novel numerical-iterative-approach for strain-softening surrounding rock incorporating rockbolts effectiveness and hydraulicmechanical coupling based on three-dimensional HoekBrown strength criterion," Tunnelling and Underground Space Technology, vol. 101, article 103358, 2020.

[34] Q. He, Y. Li, and S. She, "Mechanical properties of basalt specimens under combined compression and shear loading at low strain rates," Rock Mechanics and Rock Engineering, vol. 52, no. 10, pp. 4101-4112, 2019.

[35] L. Zou, L. Jing, and V. Cvetkovic, "Modeling of flow and mixing in 3D rough-walled rock fracture intersections," Advances in Water Resources, vol. 107, pp. 1-9, 2017.
[36] E. Hoek and Z. T. Bieniawski, "Brittle fracture propagation in rock under compression," International Journal of Fracture Mechanics, vol. 1, no. 3, pp. 137-155, 1965.

[37] H. Sonmez, E. Tuncay, and C. Gokceoglu, "Models to predict the uniaxial compressive strength and the modulus of elasticity for Ankara Agglomerate," International Journal of Rock Mechanics and Mining Sciences, vol. 41, no. 5, pp. 717-729, 2004.

[38] L. N. Germanovich, R. L. Salganik, A. V. Dyskin, and K. K. Lee, "Mechanisms of brittle fracture of rock with pre-existing cracks in compression," Pure and Applied Geophysics, vol. 143, no. 1-3, pp. 117-149, 1994.

[39] S. Wu, H. Chen, H. Lamei Ramandi et al., "Investigation of cable bolts for stress corrosion cracking failure," Construction and Building Materials, vol. 187, pp. 1224-1231, 2018.

[40] N. Erarslan and D. J. Williams, "Mixed-mode fracturing of rocks under static and cyclic loading," Rock Mechanics and Rock Engineering, vol. 46, no. 5, pp. 1035-1052, 2013.

[41] L. Yin and J. Chen, "Experimental study of influence of seepage pressure on joint stress-seepage coupling characteristics," Rock and Soil Mechanics, vol. 34, no. 9, pp. 2563-2568, 2013.

[42] Y. Yan, E. Wang, and S. Wang, "Numerical simulation of rheological properties of rocks in seepage field," Rock and Soil Mechanics, vol. 31, no. 6, pp. 1943-1949, 2010.

[43] J. Liu, Z. Yu, R. Wang, and J. Li, "Research on seepage law of splitting sandstone with non-fillers under multiple factors," Journal of Hydraulic Engineering, vol. 47, no. 1, pp. 54-63, 2016.

[44] T. A. Krouskop, T. M. Wheeler, F. Kallel, B. S. Garra, and T. Hall, "Elastic moduli of breast and prostate tissues under compression," Ultrasonic Imaging, vol. 20, no. 4, pp. 260 274, 1998.

[45] P. K. Kaiser, S. Yazici, and J. Nosé, "Effect of stress change on the bond strength of fully grouted cables," International Journal of Rock Mechanics and Mining Sciences \& Geomechanics Abstracts, vol. 29, no. 3, pp. 293-306, 1992.

[46] F. Langebrake, D. Fuchs, and H. Nöller, "Non-destructive testing of ground-anchors of bridge structures," in International Symposium on Non-Destructive Testing in Civil Engineering (NDT-CE), NDTnet, Berlin, 1997. 